\title{
Addition of Magnetic Markers for Non-destructive Evaluation of Polymer Composites
}

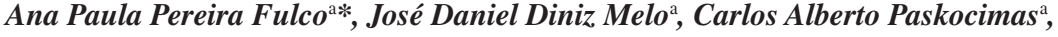 \\ Suzana Nóbrega de Medeiros ${ }^{\mathrm{b}}$, Fernando Luis de Araujo Machado ${ }^{\mathrm{c}}$, Alexandre Ricalde Rodrigues ${ }^{\mathrm{c}}$ \\ ${ }^{a}$ Departamento de Engenharia de Materiais, Universidade Federal do Rio Grande do Norte - UFRN, \\ Natal, RN, Brazil \\ ${ }^{b}$ Departamento de Física, Universidade Federal do Rio Grande do Norte - UFRN, \\ Natal, RN, Brazil \\ ${ }^{c}$ Departamento de Física, Universidade Federal Pernambuco - UFPE, \\ Recife, PE, Brazil
}

Received: March 24, 2011; Revised: August 2, 2011

\begin{abstract}
Polymer composite pipes are an appealing option as a substitute for conventional steel pipes, particularly due to their inherent corrosion resistance. However, the composite pipes currently used do not allow non-destructive evaluation (NDE) using instrumented devices which operate with magnetic sensors. The present work aims at the development of polymer composites with the addition magnetic markers to allow the application nondestructive evaluation techniques which use magnetic sensors. Glass-polyester composite flat, circular plates were fabricated with the addition of ferrite particles (barium ferrite and strontium ferrite) and four types of notches were introduced on the plates' surfaces. The influence of these notches on the measured magnetic properties of each material was measured. X-ray diffraction (XRD), X-ray fluorescence (XRF) and Brunauer, Emmett, and Teller (BET) nitrogen adsorption were used for the characterization of the ferrite particles. Particle dispersion in the polymer matrix was analyzed by scanning electron microscopy (SEM). According to the results, a particular variation in magnetic field was detected over the region surrounding each type of notch. The results suggest that the proposed technique has great potential for damage detection in polymer composites using magnetic sensors and thus constitute a valuable contribution which may ultimately lead to the development of non-destructive evaluation techniques for assessing the structural integrity polymer composite pipes.
\end{abstract}

Keywords: composite materials, magnetic markers, non-destructive evaluation

\section{Introduction}

Steel pipelines are commonly used in the petroleum industry for the transport of oil and gas. However, corrosion leads to reduced time life of these components and the need for frequent inspection, repairs or replacement. Polymer matrix composite pipes, alternatively, offer advantages over steel tubes for this application due to the corrosion resistance inherent to this type of material and other benefits such as weight reduction ${ }^{1-4}$. Many types of resins and fiber reinforcement materials are currently used in composites for oilfield applications. While glass is the typical reinforcement material, polyester, vinyl ester, and epoxy are the most prevalent resins ${ }^{1}$. Nonetheless, the conventional polymer composite pipes currently used do not allow non-destructive evaluation (NDE) using instrumented pigs which operate with magnetic sensors.

Approaches to detect damage and internal defects in polymer composite materials are of great interest, both for quality control during the production stages, as well as for in-service inspections and during maintenance operations. The use of non-destructive evaluation (NDE) techniques is necessary to access structural integrity without causing damage to the materials. NDE techniques currently used to examine composite materials include ultrasound, thermography, shearography and X-ray computed tomography (XR-CT) ${ }^{5-7}$.
Shearography has been used for nondestructive evaluation of composites including delamination detection with various types of excitation loads including thermal, vacuum and internal pressure ${ }^{6}$. Thermography has also been proven capable of evaluating internal defects in composites. Although the technique is highly sensitive to detect delamination, there are limitations for high-thickness measurements ${ }^{6}$. X-ray CT provides very high resolution images and complete $3 \mathrm{D}$ reconstruction of the part evaluated and can detect defects such as voids, cracks, inclusions, dry fibers and delaminations. In this case, the parts to be tested can be thick due to the relatively low X-ray attenuation of the polymer composites. Ultrasonic techniques have been extensively used for inspection of metallic parts for flaw detection/evaluation, dimensional measurements, material characterization ${ }^{7}$. In composites, ultrasonic inspection is able to detect delaminations and provide in-depth information, even relatively thick parts.

Magnetic flux leakage (MFL) is the most used technique for the inspection of steel pipelines in the petroleum industry ${ }^{8}$. However, this technique is not suitable for polymer composites since the material cannot be magnetized. Thus, the addition of magnetic particles to polymer matrix composites offers great potential to allow inspection of these materials using NDE techniques that are sensitive to 
changes in magnetic field. When there is a defect in the material to be inspected, there are distortions in the magnetic field detected by transducers and converted into electronic signals ${ }^{9}$.

Ferrites are magnetic materials with a special characteristic: they have spontaneous magnetic induction in the absence of an external magnetic field. Ferrites are a well established family of magnetic materials, which are inexpensive and chemically stable. Thus, this large class of ceramic materials ${ }^{10}$ has a wide range of technological applications.

The objective of this work was to study the variations in magnetic field around notches in polymer composite plates with the addition of magnetic markers. Two types of ferrite (barium and strontium) were used as magnetic markers and four types of notches were introduced on the surface of the plates. The measurements indicated that each notch produced a characteristic signature in the magnetic field.

\section{Experimental}

Composite circular plates were fabricated by hand lay-up with a diameter of $500 \mathrm{~mm}$ for the magnetic characterization. The materials used were: balanced plain weave fabric E-glass $\left(450 \mathrm{~g} . \mathrm{m}^{-2}\right)$, orthophthalic polyester, barium ferrite particles (for type 1 disk) and strontium ferrite particles (for type 2 disk). Both ferrites were acquired from FERMAG - Ferritas Magnéticas Ltda - BRAZIL. Polyester resin was mixed with the ferrite particles using a mix ratio in parts by weight (pbw) of 90:10 (resin: particles). A mechanical shaker with speed of $1750 \mathrm{rpm}$ was used to disperse the ferrite particles in the polymer matrix for a period of 20 seconds. Then, the layers of glass fabric impregnated with the liquid mixture (polyester resin combined with ferrite particles) were laid up to form a laminated composite with fifteen layers. Rollers were used on each layer to help remove air bubbles and promote compaction. After the cure of the polymer resin was complete, the plates were cut into a circular shape using a diamond abrasive saw. Four types of notches were then introduced onto the composite disks using a drill. Figure 1 shows the composite disk with notches.

Before the fabrication of the disks, the ferrites were analyzed on a Shimadzu EDX-820 Energy Dispersive X-ray Fluorescence Spectrometer for the determination of the chemical composition. $\mathrm{X}$-ray diffraction patterns of samples of ferrite particles were determined on a X-ray diffractometer XRD-6000 Shimadzu, with copper tube $(\lambda=1.5418 \AA)$. The scan was perfomed over the range $20-80^{\circ}(2 \theta)$. The surface area, pore diameter and average pore volume of the ferrites were obtained by determining the adsorption isotherms of $\mathrm{N}_{2}(\mathrm{~g})$ at $77 \mathrm{~K}$ in a Micromeritics ASAP 2010 using the BET method (Brunauer, Emmet and Teller). These parameters are important to determine the morphology of the particles and the existence of agglomerates.

The particle dispersion in the composite was observed using a scanning electron microscope (SEM) Shimadzu SSX-550, where the images were generated using backscattered electron (BSE) imaging. SEM has been used by other authors to observe particle dispersion and the presence of agglomerates in polymeric composites with micronand nano-sized particles ${ }^{11-13}$. Variations in the magnetic field on the composite disks with the addition of magnetic particles (barium and strontium ferrites) were measured using a custom-made apparatus (Figure 2). The disks were mounted on a shaft of a stepper motor in which it was possible to control the speed and direction of spin. A magnet was kept fixed near the disk and a Hall effect sensor, also fixed and connected with a FW Bell gaussmeter capable of measuring three perpendicular components of the magnetic field, was kept close to the magnet. The magnetic field produced by magnetization of the samples and the distortion of the magnetic field produced by the

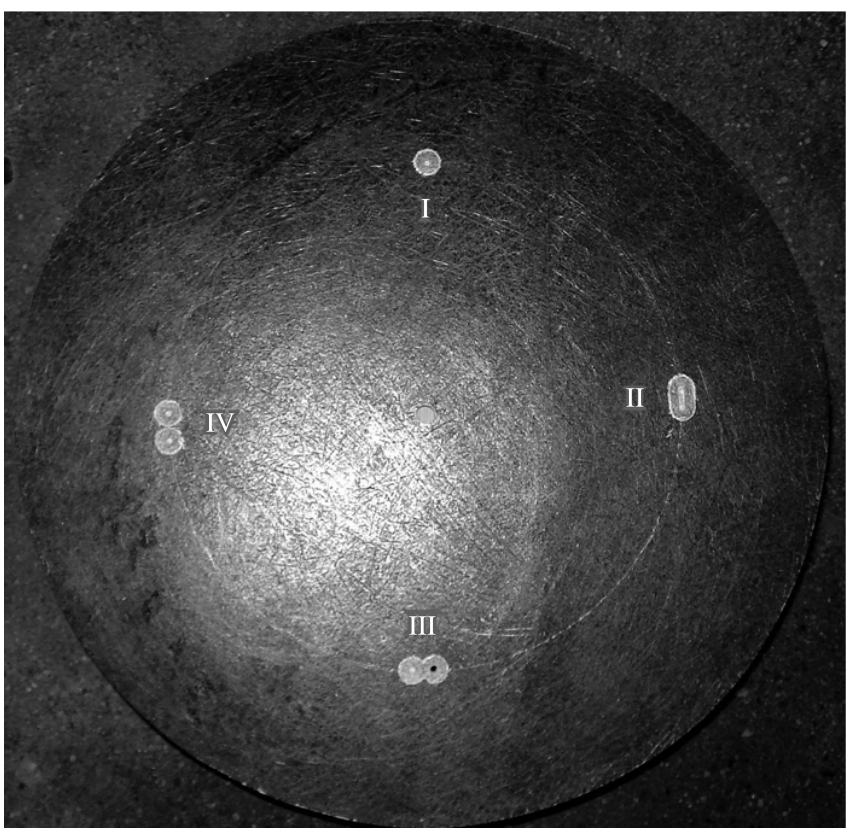

Figure 1. Polymer matrix composite disk with notches.

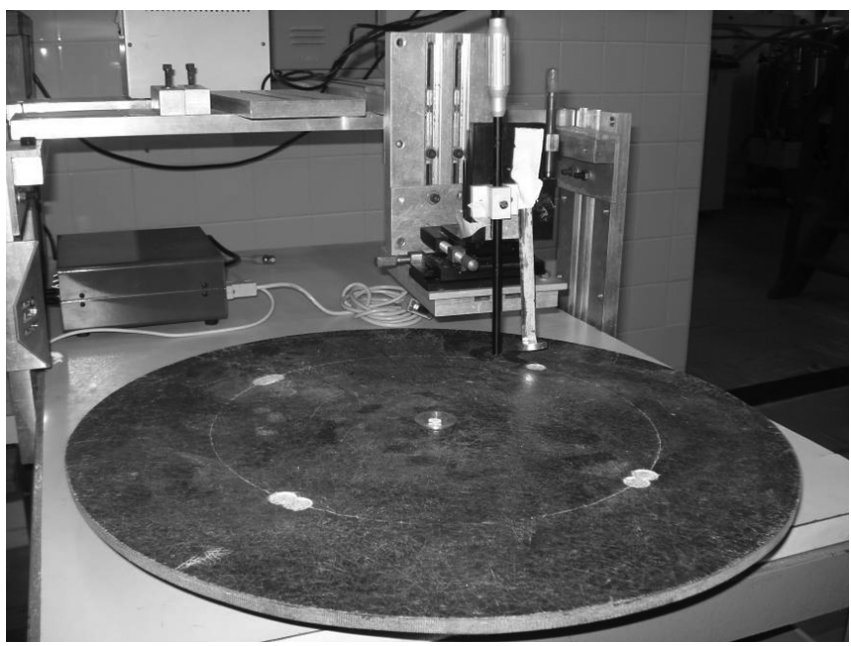

Figure 2. Equipment for measuring the magnetic field.

Table 1. Chemical composition of barium ferrite and strontium ferrite obtained by X-ray fluorescence.

\begin{tabular}{cccc}
\hline \multicolumn{2}{c}{ Barium ferrite } & \multicolumn{2}{c}{ Strontium ferrite } \\
\hline $\begin{array}{c}\text { Chemical } \\
\text { elements }\end{array}$ & $\begin{array}{c}\text { Composition } \\
(\text { wt. }(\%))\end{array}$ & $\begin{array}{c}\text { Chemical } \\
\text { elements }\end{array}$ & $\begin{array}{c}\text { Composition } \\
\text { (wt. (\%)) }\end{array}$ \\
\hline $\mathrm{Fe}$ & 81.100 & $\mathrm{Fe}$ & 89.739 \\
$\mathrm{Ba}$ & 17.724 & $\mathrm{Sr}$ & 9.101 \\
$\mathrm{~S}$ & 0.428 & $\mathrm{~S}$ & 0.447 \\
$\mathrm{Si}$ & 0.379 & $\mathrm{Ba}$ & 0.404 \\
$\mathrm{Sr}$ & 0.369 & $\mathrm{Mn}$ & 0.267 \\
& & $\mathrm{~V}$ & 0.040 \\
\hline
\end{tabular}




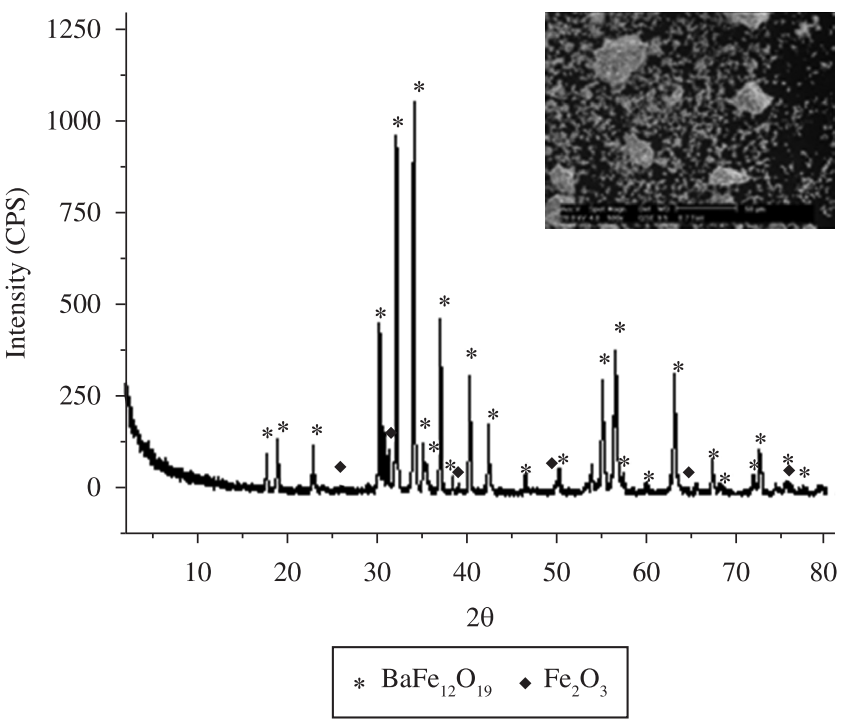

Figure 3. X-ray diffractogram and SEM micrograph of barium ferrite particles.
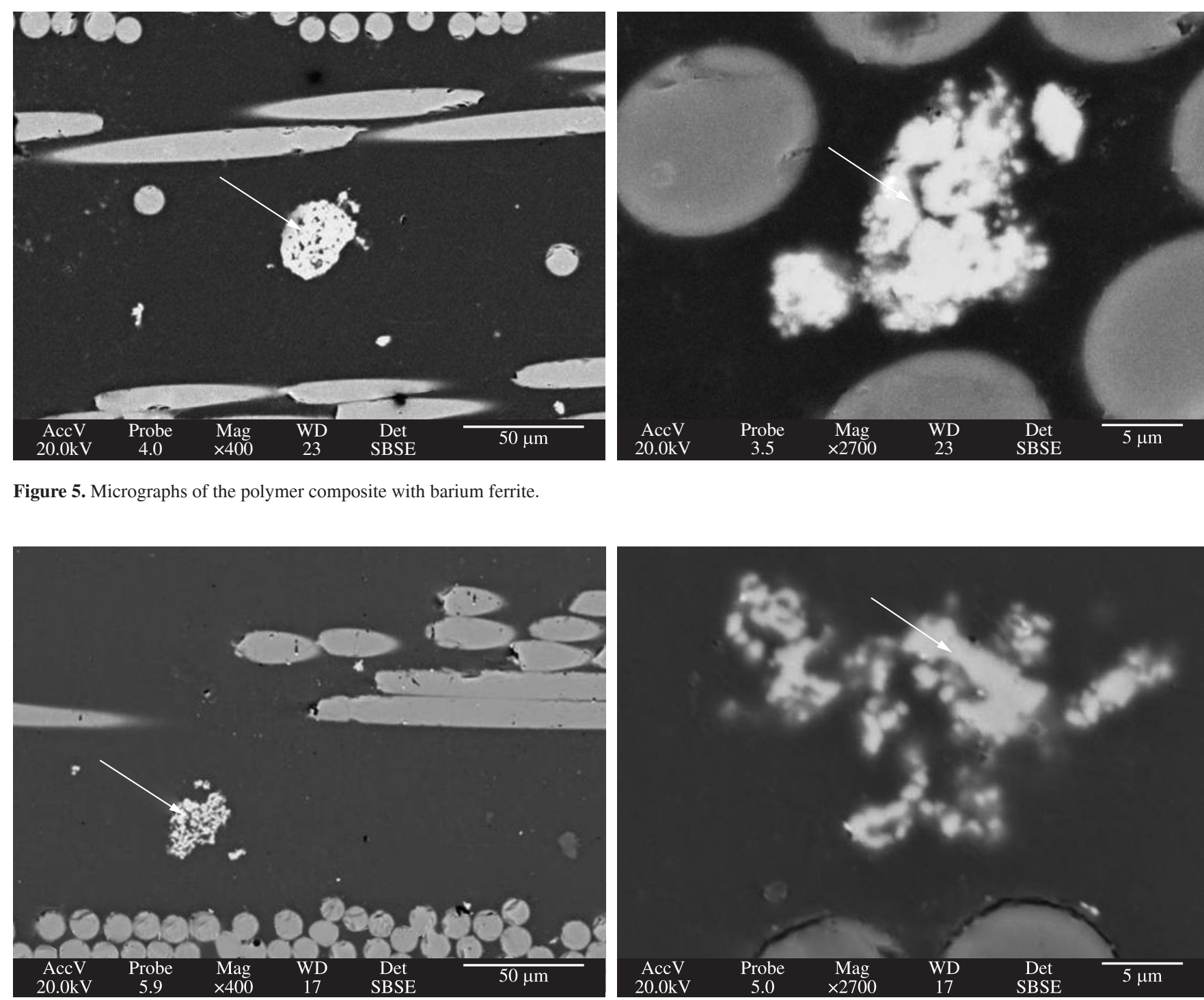

Figure 6. Micrographs of the polymer composite with strontium ferrite.

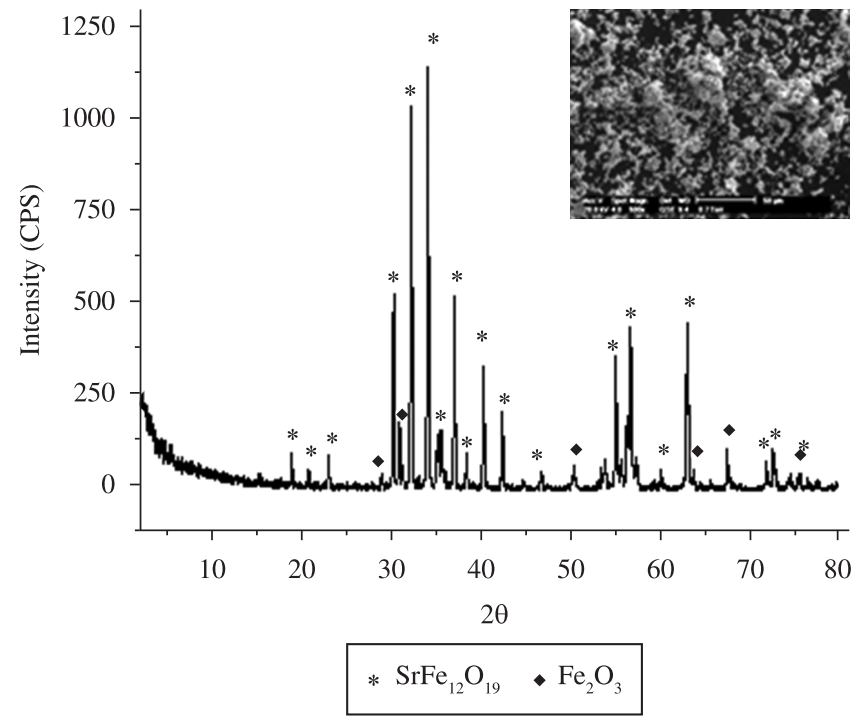

Figure 4. X-ray diffractogram and SEM micrograph of strontium ferrite particles.

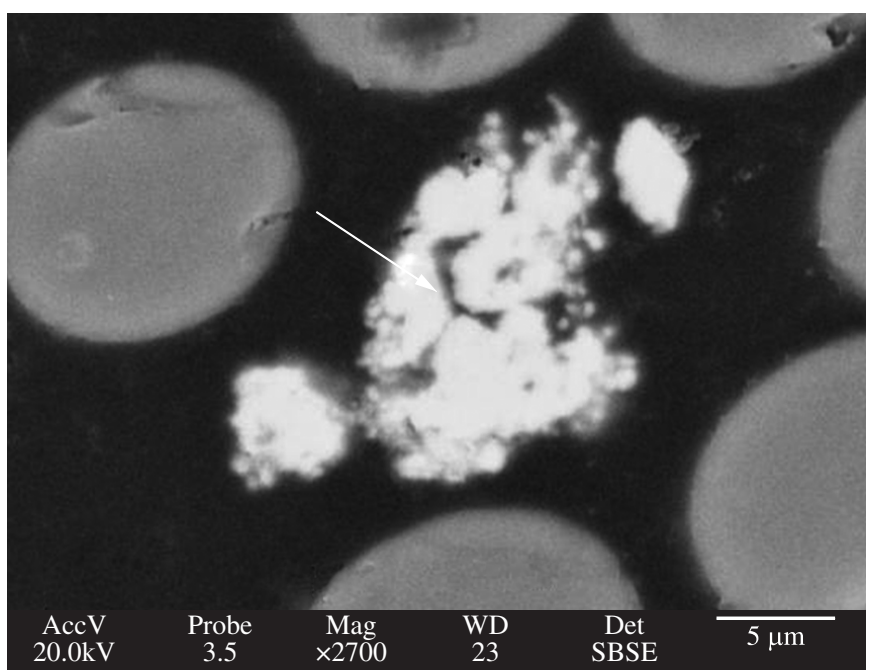

3.5

2700

SBSE

\footnotetext{
Figure 5. Micrographs of the polymer composite with barium ferrite.
} 
notches were detected by the sensor. Data were acquired through a computer using a GPIB interface controlled by a program in Labview.

To verify the repeatability of the results, the direction of rotation of the disks was reversed over the limits of each notch. Symmetrical curves about the point of return would indicate a clear contribution of the notch for the deformation of magnetic field lines over the region. Each notch region was measured three times, in both directions.

\section{Results and Discussion}

The results of X-Ray Fluorescence obtained for the two types of ferrites are presented in Table 1.

The results presented in Table 1 indicate that the relations in percentage by weight for barium ferrite are very close to the values of stoichiometric barium hexaferrite. Thus, the presence of residual iron oxide can be attributed to stoichiometric deviations generated during the manufacturing process. In other hand, the results for the

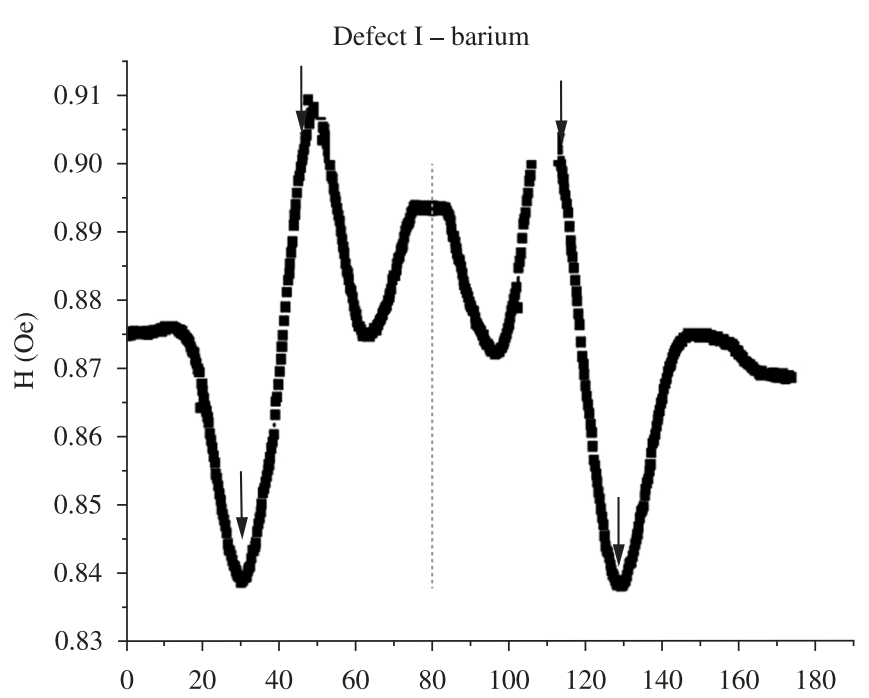

(a)

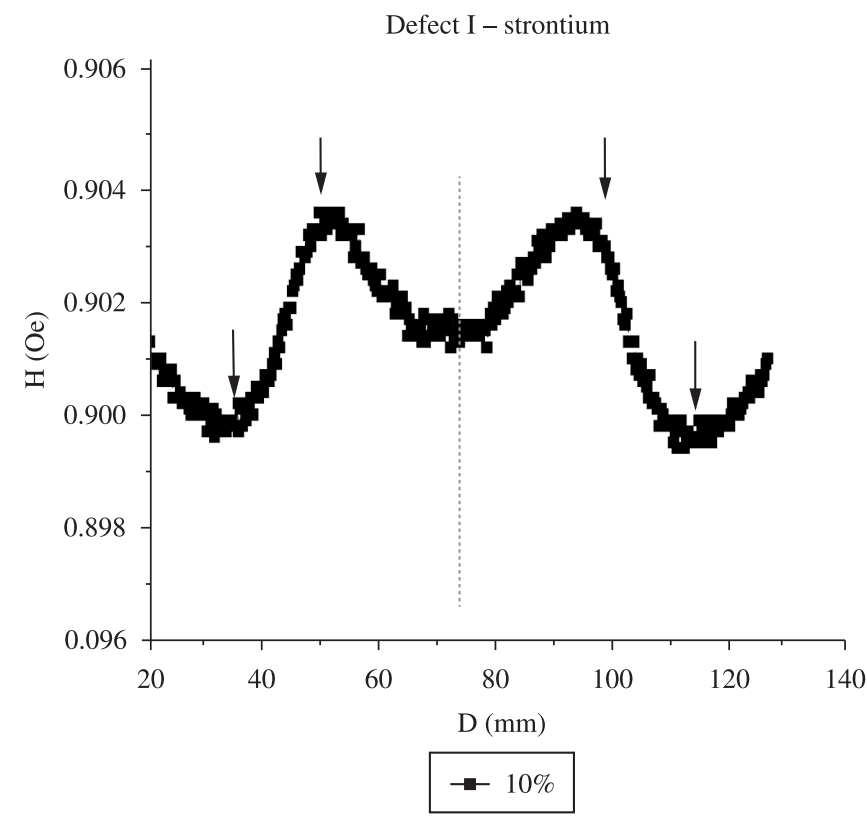

(b)

Figure 7. Magnetic field (Oe) vs. distance (mm) for the notch I. ferrite strontium show a strontium excess superior of $3 \%$ by weight, which is associated with the presence of residual iron oxide identified by $\mathrm{XRD}$, suggesting that the production process is more subject to variations in of stoichiometry. The level of impurities found for the two systems arises from the use of industrial raw materials and ores containing $\mathrm{S}, \mathrm{Si}, \mathrm{Mn}$ and $\mathrm{V}$.

Figures 3 and 4 present the X-ray diffractograms for barium ferrite and strontium ferrite, respectively. The results show that the particles consist primarily of $\mathrm{BaFe}_{12} \mathrm{O}_{19}$ and $\mathrm{SrFe}_{12} \mathrm{O}_{19}$ and iron oxide as a secondary phase. It was found that the presence of iron oxide is particularly marked in the sample of strontium ferrite. The presence of iron oxide is normally due to the excess of its precursor which is intentionally added during the production process of the ferrite. Its presence produces a magnetic response which competes with that of the ferrite. However, in the current application one detects the overall

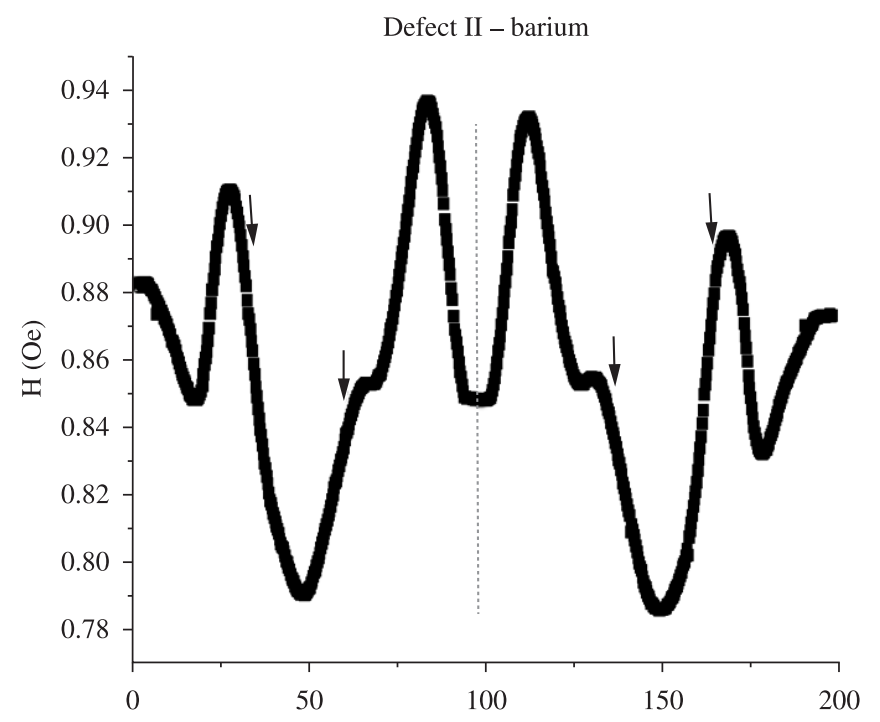

(a)

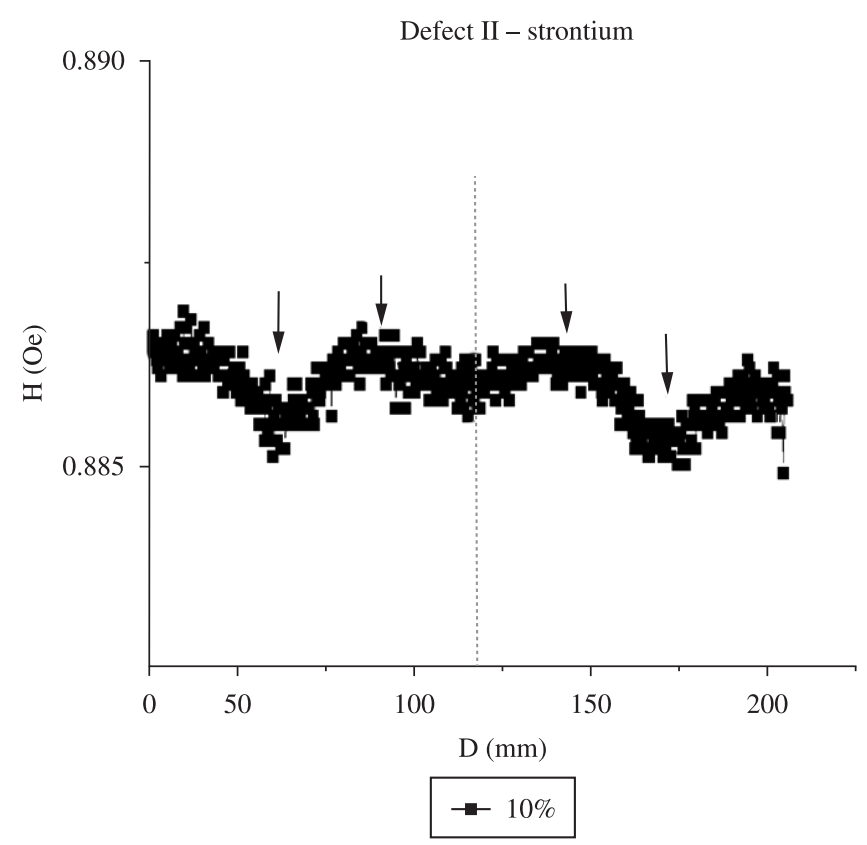

(b)

Figure 8. Magnetic field (Oe) vs. distance (mm) for the notch II. 
magnetic response from the magnetic material and, as long as the composition remains unmodified, the presence of small amounts of residual iron oxide should not result in any negative effect to the properties of the product.

BET measured specific surface area for the barium ferrite was $1.3928 \mathrm{~m}^{2} \cdot \mathrm{g}^{-1}$, while for the strontium ferrite the measured specific surface area was $1.0283 \mathrm{~m}^{2} \cdot \mathrm{g}^{-1}$. These low surface areas of the two materials are consistent with the microscopy results which indicated the presence of agglomerates.

Figure 5 corresponds to the SEM image of the microstructure of polymer composites containing barium ferrite. The backscattered electron images suggest the presence of agglomerates of ferrite in the polymer matrix distributed between the layers of glass fiber reinforcement. These agglomerates were observed throughout the entire composite sample analyzed. The presence of agglomerates is undesirable, since they are expected to affect the magnetic response of the material. In practical terms these agglomerates may thwart the detection of micron-sized defects or the differentiation of the contour in some types of defects in this size domain. However, the magnetic non-destructive analysis was used in this work to detect defects larger than several millimeters in size. In addition, the distribution of particles can be improved by controlling the dispersion in the polymer by properly mixing the composites under ultrasound or by using a mechanical shaker as done in the present work.

Figure 6 shows the microstructure of the polymer composite containing strontium ferrite. This sample also revealed the presence of agglomerates, with the same negative implications as previously discussed. In both systems, it was found that the micron size ferrite particles formed agglomerates with sizes exceeding 10 microns.

Figures 7-10 present the changes in magnetic field (Oe) measured perpendicular to the plane of the samples versus distance $(\mathrm{mm})$ for the notches I, II, III and IV (Figure 1), respectively. Each figure shows the results for the composites with the addition of barium and strontium ferrite. The beginning and end of each notch marked in the figures

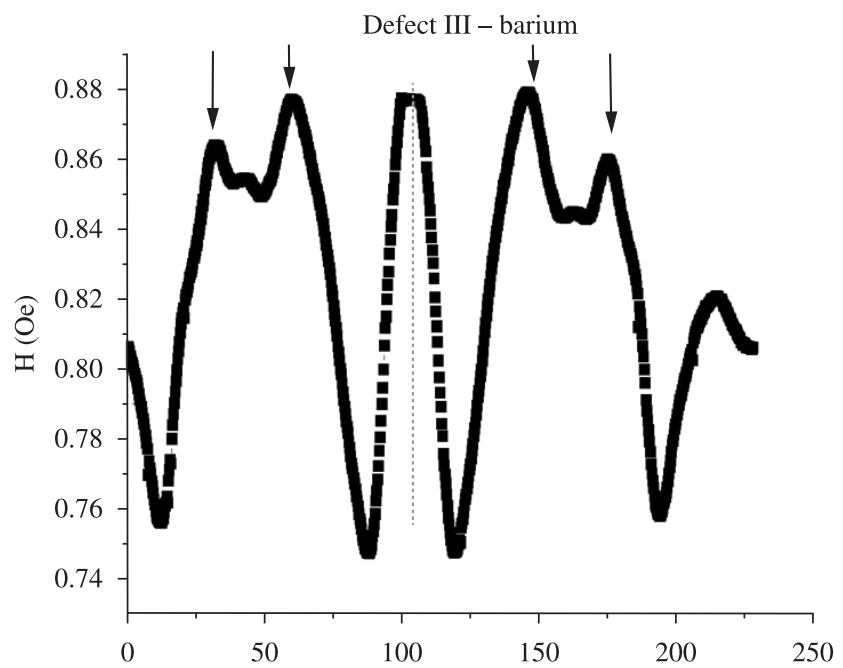

(a)



(b)

Figure 9. Magnetic field (Oe) vs. distance (mm) for the notch III.

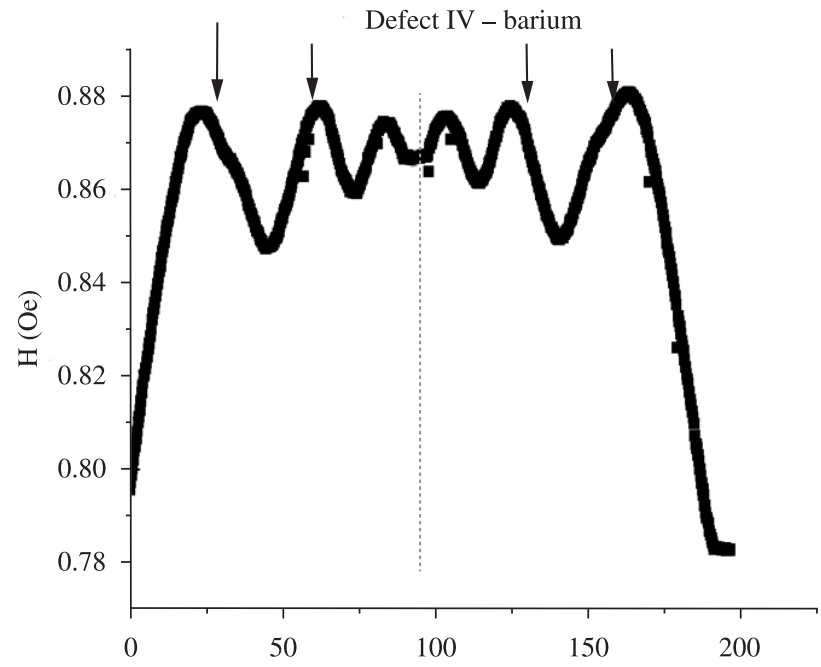

(a)

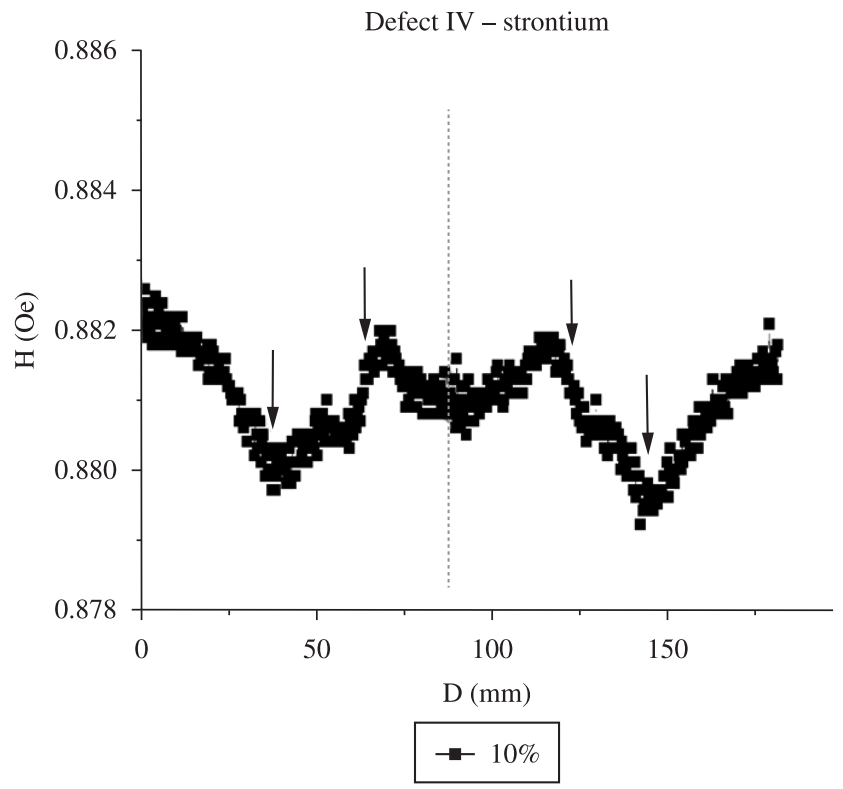

(b)

Figure 10. Magnetic field (Oe) vs. distance (mm) for the notch IV. 
coincide with the dimensions determined in disks. Notches I, II, III and IV have lengths respectively of $16,30,28$ and $32 \mathrm{~mm}$, thereby confirming that the signal obtained is characteristic of each notch. The repeatability of the measured signals was also assessed using measurements in clockwise and counterclockwise directions, which in this case the same shape of the curve that represents the measured magnetic field versus distance was verified. The dashed line in the figures indicates the location where the rotation was reversed. Each notch region was measured three times, in both directions, and no difference was observed in the measured data.

The results presented in Figures 7-10 clearly indicate the variation in magnetic field produced by presence of notches. It is observed that the signals measured in disks with barium ferrite are better defined, with a clear indication of the beginning and end of the notch, and a particular shape for each type of notch. The difference between the magnetic signals measured in composites with strontium and barium ferrites is believed to be related to the difference in atomic weight of $\mathrm{Sr}$ and $\mathrm{Ba}-$ atomic weight of $\mathrm{Sr}$ is $64 \%$ of the atomic weight of $\mathrm{Ba}-$ considering the fact that both composite materials were prepared using the same parts by weight. Thus, the particles in the material with the strontium ferrite are closer to each other than in the barium one which, in turn, it is more influenced by the demagnetizing dipolar interaction among those particles. A smaller separation among particles can also favor the formation of more agglomerates as indicated by the BET data. These effects in addition to the intrinsic magnetic response of each system should be further evaluated in future work.

\section{Conclusions}

In this work, circular glass/polyester composite plates with the addition of magnetic particles of barium or strontium ferrites (10 wt. $(\%)$ ) were produced. Four notches were introduced on the composite plates and the variations in magnetic field produced by the presence of notches were measured. Variations in magnetic field were detected in regions surrounding the notches. Moreover, each type of notch produced a particular change in magnetic field measured along the circumferential path which includes the notches. SEM images indicated the presence of agglomerates of magnetic particles in some regions of the plates, which are known to affect the magnetic field even in the absence of notches. Nevertheless, signs of change in magnetic field due to notches were reproducible and characteristic for each type of notch. Composites with the addition of barium ferrite presented curves with less dispersion and better correlation with the geometry of notches. The results indicate that the proposed technique has great potential for damage detection in polymer matrix composites.

\section{Acknowledgements}

ANP - National Agency of Petroleum, Natural Gas and Biofuels is acknowledged for the fellowship support of the author Ana Paula Pereira Fulco during the development of this work, as part of PRH-30.
The authors are also grateful to Evans P. C. Ferreira of Tecniplas Nordeste Plásticos Reforçados Ltda - Brazil for his valuable support during the fabrication of the composite plates. FERMAG - Ferritas Magnéticas Ltda - BRAZIL is acknowledged for the generous donation of the ferrites used in this investigation. Work partially supported by CNPq, FACEPE and FINEP.

\section{References}

1. Hossain ME. The current and future trends of composite materials: an experimental study. Journal of Composite Materials. 2011.

2. Yang C. Design and analysis of composite pipe joints under tensile loading. Journal of Composite Materials. 2000; 34:332-349.

3. Perreux D and Suri C. A study of the coupling between the phenomena of water absorption and damage in glass/epoxy composite pipes. Composites Science and Technology. 1997; 57:1403-1413. http://dx.doi.org/10.1016/ S0266-3538(97)00076-6

4. Frost SR and Cervenka A. Glass fibre-reinforced epoxy matrix filamentwound pipes for use in the oil industry. Composites Manufacturing. 1994; 5(2):73-81. http://dx.doi.org/10.1016/0956-7143(94)90058-2

5. Huang YD, Froyen L and Wevers M. Quality control and non-destructive test in metal matrix composites. Journal of Nondestructive Evaluation. 2001; 20(3):113-32. http://dx.doi.org/10.1023/A:1013503005743

6. Amenabar I, Mendikute A, López-Arraiza A, Lizaranzu M and Aurrekoetxea J. Comparison and analysis of non-destructive testing techniques suitable for delamination inspection in wind turbine blades. Composites: Part B. 2011; 42:1298-1305. http://dx.doi.org/10.1016/j. compositesb.2011.01.025

7. Bayraktar E, Antolovich SD and Bathias C. New developments in non-destructive controls of the composite materials and applications in manufacturing engineering. Journal of Materials Processing Technology. 2008; 206:30-44. http://dx.doi.org/10.1016/j.jmatprotec.2007.12.001

8. Gloria NBS, Areiza MCL, Miranda IVJ. and Rebello JMA. Development of a magnetic sensor for detection and sizing of internal pipeline corrosion defects. NDT \& E International. 2009; 42(8):669-677. http://dx.doi. org/10.1016/j.ndteint.2009.06.009

9. Mix PE. Introduction to Nondestructive Testing. Austin, Texas: John Willey \& Sons Inc.; 2005.

10. Sugimoto M. The Past, Present, and Future of Ferrites. Journal of the American Ceramic Society. 1999; 82(2):269-80.

11. Cho J, Joshia MS and Sun CT. Effect of inclusion size on mechanical properties of polymeric composites with micro and nano particles. Composites Science and Technology. 2006; 66(13):1941-1952. http://dx.doi.org/10.1016/j.compscitech.2005.12.028

12. Singh RP, Zhang M and Chan D. Toughening of a brittle thermosetting polymer: Effects of reinforcement particle size and volume fraction. Journal of Materials Science. 2002; 37:781-788. http://dx.doi. org/10.1023/A:1013844015493

13. Melo JDD, Almeida CRR, Paskocimas CA, Mendonça RM and Medeiros AM. High Energy Mill Processing of Polymer Based Nanocomposites. Journal of Composite Materials. 2008; 42(22):2363-2375. 